\title{
Novel approaches reveal unexpected biogeochemical dynamics in extreme environments
}

\author{
SAMANTHA B JOYE", ANDREW MONTOGOMERY', \\ KIMBERLEY S. HUNTER', GUANG-CHAO ZHUANG' ${ }^{2}$, AND \\ LAURA LAPHAM ${ }^{2}$ \\ Dept. of Marine Sciences, Univ. of Georgia, Athens, GA \\ 30602-3636 USA (*correspondance-mjoye@uga.edu, \\ montgoam@uga.edu,kshunter@uga.edu) \\ Ocean Univ. of China, Key Lab. of Marine Chemistry, \\ Qingdao, China (zgc@ouc.edu.cn) \\ 'Center for Environ. Studies, Univ. of Maryland, Solomons, \\ MD 20688 (lapham@umces.edu)
}

Deep ocean extreme environments, where locales are characterized by high pressure and radical deviations in physico-chemical parameters such as oxygen, $\mathrm{pH}$, and temperature, offer a unique opportunity to explore the regulation and connectivity of elemental cycling. We developed a suite of approaches to better characterize deep ocean extreme habitats and to track microbial activity under quasi in situ conditions $[1,2]$. These methods revealed unanticipated patterns of metabolism and biogeochemical coupling [3,4,5], providing insight into biogeochemical dynamics and regulation. Our work assessed the effects of temperature, substrate availability, and geochemical regime on key carbon cycling processes, such as anaerobic oxidation of methane, sulfate reduction, metahanogenesis, by tracking the fate of low molecular weight organic compounds. We collected sediments from the Guaymas Basin where temperatures ranged between 4 to $\sim 100^{\circ} \mathrm{C}$, assessed geochemical signatures, and used $\mathrm{C}$ radiotracers to quantify metabolic rates. The results reveal the microbial and biogeochemical regulation of elemental cycling in these environments under realistic conditions. The dynamic nature of these habitats is poised microbially, by metabolic phasing, where biogeochemical processes phase in and out as a function of electron acceptor availability. Metabolic phasing may be a characteristic of high flux, high activity ecosystems, promoting efficient consumption of carbon substrates and promoting microbial diversity in hydrothermal environments.

References.

[1] Bowles et al (2011) Limnol. Oceanogr. Meth. 9, 499-509.

[2] Zhuang et al. (2018) Environ. Microbiol. https://bit.ly/32gME8v. [3] Bowles et al (2019) GRL, https://bit.ly/39VNmu6. [4] Joye (2020) Ann. Rev. Earth

Planet. Sci. https://bit.ly/38ZPOzG. [5] Zhuang et al. (2019)

Geophys. Res. Let., https://bit.ly/2HHbHI 